\title{
DESAFIOS DA PRÁTICA DE ESTÁcIO EM PSICOLOGIA NO ACOLHIMENTO INSTITUCIONAL
}

Aline Cardoso Siqueira

Universidade Federal de Santa Maria

Suane Pastoriza Faraj

Universidade Federal de Santa Maria

Daiane Santos do Carmo Kemerich

Universidade Federal de Santa Maria

\section{Amanda Pereira da Silva}

Universidade Federal de Santa Maria

\section{Daniela Porto Giacomelli}

Universidade Federal de Santa Maria
Recebido em: 28/12/2019

$1^{\text {a }}$ revisão em: 22/06/2020

$2^{a}$ revisão em: 03/09/2020

Aceito em: 01/10/2020

\section{RESUMO}

Este artigo apresenta um relato de experiência de um estágio supervisionado em Psicologia realizado em uma instituição de acolhimento para crianças e adolescentes. Esse campo de estágio constitui-se em um espaço potente para a formação do estudante de Psicologia, bem como uma oportunidade de visualizar a efetivação dos direitos preconizados no ECA em 1990. Assim, objetiva-se problematizar os desafios dessa medida de proteção e apontar possibilidades para garantir os direitos da população infanto-juvenil nos 30 anos do ECA. Os resultados sinalizam desafios relacionados à garantia do direito à educação, lazer, atendimento especializado, convivência familiar e comunitária e tempo de permanência na instituição. Foram realizados atendimentos psicológicos, reuniões nas escolas, atendimentos psicossociais, oficinas para adolescentes, busca por atividades de lazer e esporte, etc. Conclui-se que o esforço para a efetivação do ECA deve ser tarefa constante, sendo potencializada com a relação acolhimento/universidade.

Palavras-chave: acolhimento institucional; estágio supervisionado; direitos das crianças e dos adolescentes; Estatuto da Criança e do Adolescente. 


\section{CHALLENGES OF SUPERVISED PRACTICE IN A CHILDCARE INSTITUTION}

\section{ABSTRACT}

This paper presents an experience report of a supervised internship in Psychology held at an institutional care for children and adolescents. The institutional care field constitutes a potent space for the training of Psychology students, as well as an opportunity to visualize the realization of the rights provided for in the ECA in 1990. Thus, the objective is to problematize the challenges of this law and to point out possibilities to guarantee the children and youth rights in the 30 years of the ECA. The results indicate challenges related to guaranteeing the rights to education, leisure, specialized care, family and community life, and residence time at the institution. During the internship, students carried out psychological assistance, school meetings, psychosocial assistance, groups, searches for leisure and sports activities, etc. In conclusion, the effort for the ECA establishment must be a constant task, enhanced by the institution/university relationship.

Keywords: institutional care; supervised practice; children and adolescents rights; Brazilian Statute for Children and Adolescents.

\section{DESAFÍOS EM LA PRÁCTICA SUPERVISIONADA EM UNA INSTITUCIÓN DE ACOGIMIENTO}

\section{RESUMEN}

Este artículo presenta un relato de experiencia de práctica supervisada en Psicología realizada en una institución de acogimiento para niños y adolescentes. Una institución de acogimiento constituye un potente espacio para la formación en Psicología, así como una oportunidad para visualizar la realización de los derechos defendidos en el ECA en 1990. Así, el objetivo es problematizar los desafíos de esta medida de protección y señalar posibilidades para garantizar los derechos de la población infantil y juvenil en los 30 años de ECA. Los resultados señalan desafíos con la garantía de los derechos a la educación, el ocio, la atención especializada, la vida familiar y comunitaria y el tiempo de estancia. Durante las prácticas se realizaron asistencia psicológica, reuniones en las escuelas, asistencia psicosocial, talleres para adolescentes, búsqueda de actividades lúdicas y deportivas. Se concluye que el esfuerzo por realizar el ECA debe ser constante, potenciada con la relación acogimiento/universidad.

Palabras clave: acogimiento institucional; práctica supervisada; derechos de la niñez y la adolescencia; Estatuto Brasileño para niños y adolescentes. 


\section{INTRODUÇÃO}

Em muitos países, um número considerável de crianças e adolescentes é afastado do convívio familiar e acolhido em instituições como medida de proteção e garantia de direitos (Machado, Scott, \& Siqueira, 2016). No Brasil, o acolhimento institucional está previsto no Estatuto da Criança e do Adolescente (ECA) como medida protetiva provisória e excepcional, sendo aplicada quando os responsáveis e/ou famílias não conseguem cumprir a função de proteção e cuidado, colocando a criança/adolescente em uma situação de risco. A medida visa à reinserção familiar ou inserção em família substituta (Presidência da República, 1990).

O ECA estabeleceu o reordenamento das instituições de acolhimento, instituindo que crianças e adolescentes fossem acolhidas em unidades institucionais pequenas, com poucos acolhidos. Além disso, esta lei preconizou a maior participação das crianças/adolescentes em atividades ofertadas pela comunidade, a fim de promover a escolarização, profissionalização, desenvolvimento e convivência familiar e comunitária dos sujeitos acolhidos. Também foi previsto no ECA a preservação dos vínculos familiares, sendo sugerido a não separação de irmãos (Presidência da República, 1990). No entanto, estudos atuais sobre o tema evidenciaram as dificuldades dos acolhidos em manter a frequência nas instituições escolares (Acioli, Barreira, Lima, Assis, \& Lima, 2019); pouca oferta de atividades desenvolvidas nas instituições de acolhimento institucional (Heumann \& Cavalcante, 2018); dificuldade dos acolhidos manter vínculos com a família e comunidade (Cruz, Cardoso, \& Matos, 2018); e carência da oferta do atendimento especializado na área da psicologia às vítimas de violência (Faraj, Siqueira, \& Arpini, 2016).

No ano de 2010, foi promulgada a Lei 12.010 de 2009 que dispõe sobre o aperfeiçoamento da sistemática prevista para garantia do direito à convivência familiar a todas as crianças e adolescentes. Esta legislação alterou os artigos do ECA quanto à excepcionalidade e provisoriedade da medida de proteção, estabelecendo um prazo máximo de dois anos de acolhimento. Para a garantia da referida medida, foi preconizado o dever do Poder Judiciário de, em no máximo seis meses, reavaliar a situação de cada criança e adolescente acolhido. A legislação também definiu que a equipe técnica do acolhimento, formada por psicólogos e assistentes sociais, deve acompanhar a família dos acolhidos. Nesse sentido, instituiu a elaboração de um Plano Individual de Atendimento (PIA) com o intuito de atender às necessidades de cada acolhido e da sua família, buscando promover o desacolhimento de forma breve. Estas recomendações estão relacionadas à preservação dos vínculos familiares e à prevenção de problemas de saúde, como atraso no desenvolvimento cognitivo e afetivo, baixo desempenho escolar, agressividade, ansiedade e depressão (Álvares \& Lobato, 2013; Assis \& Farias, 2013; Siqueira \& Dell'Aglio, 2010).

Considerando o acolhimento institucional uma estratégia de proteção prevista no ECA em 1990, muitas crianças e adolescentes têm seus direitos assegurados e são 
salvos de vivências estressoras de toda natureza. Assim, uma vez que estes estiverem sob medida de proteção, eles devem estar inseridos em um ambiente favorável ao seu desenvolvimento, que garanta dignidade e cuidado integral. Contudo, cada instituição vivencia impasses e dificuldades para implementar a estratégia. A partir da prática do estágio acadêmico em Psicologia em uma instituição de acolhimento no Rio Grande do Sul, este trabalho tem como objetivo problematizar os desafios atrelados à execução da medida de proteção, no sentido de reconhecer suas possibilidades, propondo alternativas em prol do desenvolvimento das crianças e adolescentes.

\section{MÉTODO}

Trata-se de um relato de experiência, fruto de um estágio curricular obrigatório em um Serviço de Psicologia. Nesta seção do método, serão apresentados a contextualização do campo de estágio e participantes, características do estágio e análise dos dados.

\section{CONTEXTUALIZAÇÃO DO CAMPO DE ESTÁGIO E PARTICIPANTES}

O local do estágio mantinha três unidades de acolhimento institucional, denominadas Casas-Abrigo, localizadas em bairros residenciais, onde podiam ser acolhidos cerca de 10 crianças e adolescentes de diversas idades, cuidados por cerca de 20 educadores sociais que trabalham em regime de plantão. A equipe técnica era composta por quatro psicólogas, quatro assistentes sociais, uma enfermeira e uma nutricionista. O acolhimento firmou um convênio em 2018 com a instituição de ensino superior para efetivar a realização do estágio curricular em Psicologia.

\section{CARACTERÍSTICAS DO ESTÁGIO}

O estágio foi realizado por três estudantes do quarto ano da Graduação em Psicologia de uma Universidade Federal, tendo como base teórica a Psicologia Clínica, Psicologia do Desenvolvimento e Psicologia Jurídica. A carga horária de atuação era de 16 horas semanais na instituição, além da supervisão acadêmica semanal de duas horas prestada na Instituição de Ensino Superior. As atividades realizadas pelas estagiárias consistiam em atendimento psicossocial às famílias, crianças e adolescentes, acompanhamento de visitas domiciliares, elaboração de relatórios e Planos Individuais de Atendimento (PIA), articulação com os serviços da rede de atendimento do Município, acompanhamento de adoções, entre outros

A supervisão profissional deste estágio era prestada por uma psicóloga contratada pela instituição de acolhimento que acompanhava o cotidiano do estágio, direcionando as ações necessárias na rotina institucional e a supervisão teórica era realizada por uma psicóloga, professora adjunta da universidade à qual as estagiárias estavam vinculadas, doutora em Psicologia, a qual procurava promover 
a interlocução entre as ações e as diretrizes teóricas do campo. Foram utilizados relatórios semanais da prática desenvolvida, diário de campo e textos científicos. Também eram planejadas as atividades para serem desenvolvidas na Instituições.

\section{ANÁLISE DOS DADOS}

Os resultados foram coletados e analisados qualitativamente a partir do diário de campo e relatórios semanais das estagiárias, sendo definidas a priori (1) Direito à educação, à cultura, ao esporte e ao lazer, (2) Política de atendimento, (3) Direito à convivência familiar e comunitária, e (4) Tempo de permanência na Instituição. As reflexões propõem-se a problematizar na prática do estágio em uma instituição de acolhimento institucional que evidenciam os desafios da implementação do ECA após 30 anos.

\section{RESULTADO E DISCUSSÃO}

\section{DO dIREITO À eduCAÇÃo, À CULTURA, AO ESPORTE e AO LAZER}

A efetivação do direito à educação, à cultura, ao esporte e ao lazer evidenciou-se como um obstáculo. A partir do estágio acadêmico, identificou-se que muitos adolescentes se encontravam evadidos da escola no momento do acolhimento, sendo a sua inserção um impasse para a equipe da Instituição. A justificativa dos adolescentes para a evasão escolar prévia era diversificada, como a necessidade de trabalhar para ajudar financeiramente a família, a falta de estímulo ou exigência dos pais/cuidadores para que o adolescente estude e a falta de motivação em relação ao ensino, fatores que corroboram a literatura da área (Cano, Ferriani \& Mendonça, 1999). Uma vez acolhidos, a recusa em ir à escola e ter assiduidade era frequente, fazendo com que uma desvinculação da escola e um baixo desempenho escolar se mantivessem. Parte da manutenção desse quadro podia ser explicada pela escassez de trabalhos específicos direcionados à reinserção escolar dos acolhidos, uma vez que foi identificada uma demanda de elaboração de relatórios para o Juizado da Infância e Juventude, que tomava tempo e energia da equipe. Consequentemente, havia pouca articulação entre a escola e a equipe da instituição, não contribuindo para a assiduidade dos jovens na escola. Esse quadro se assemelha à situação de outros acolhimentos (Acioli et al., 2019; Martinez \& Soares-Silva, 2008). O estudo de Acioli e colaboradores evidenciou que somente $32,7 \%$ dos adolescentes acolhidos em Recife frequentavam a escola, pontuando a dificuldade dessa população frequentar a instituição escolar regularmente. O estudo de Martinez e Soares-Silva (2008) evidenciou que os jovens que estavam prestes a sair do acolhimento possuíam baixa escolaridade, e uma vez acolhidos, não eram incentivados a retornar a rotina escolar.

Entendendo que a educação é um direito estabelecido pelo ECA, para que toda criança e adolescente possa exercer sua cidadania e ter preparo para o mercado de trabalho; e, que permitir que eles não tenham uma relação regular e estável 
com a escola representa uma violação de direitos, as estagiárias traçaram um plano para auxiliar no fortalecimento desse direito. Na prática do estágio, entendeu-se que este direito tem que ser garantido e, nesse sentido, as acadêmicas foram até as escolas e buscaram um resgate do vínculo entre escola e equipe da instituição, promovendo um trabalho em rede. Uma possibilidade evidenciada para o retorno dos adolescentes no ambiente escolar foi a inclusão dos mesmos no Programa Jovem Aprendiz, favorecendo o retorno à escola daqueles jovens que estavam desengajados naquele momento. O Programa da Lei da Aprendizagem (PJA) é vinculado ao Ministério do Trabalho e Emprego - MTE e visa à inserção dos adolescentes e jovens no mercado de trabalho, com a exigência de que o participante frequente a escola. O PJA tem como base os dispositivos da Consolidação das Leis Trabalhistas (CLT) e do ECA para garantir aos adolescentes o direito à profissionalização. O Programa aprecia o trabalho como uma formação técnico-profissional, considerando o desenvolvimento físico, moral e psicológico do adolescente (MTE, 2014), possibilitando a qualificação profissional, sem prejuízo na formação acadêmica (Da Silva \& Costa, 2019).

Além da inserção na escola, as crianças e adolescentes precisam estar inseridos em atividades de lazer, esporte e cultura, conforme suas potencialidades e peculiaridades. No entanto, observou-se que poucos acolhidos frequentavam atividades na comunidade, permanecendo muito tempo não engajados em atividades lúdicas e/ou pedagógicas, contrariando a legislação vigente (Presidência da República, 1990). O estudo de Heumann e Cavalcante (2018) evidenciou pouca variedade de atividades desenvolvidas nas instituições de acolhimento para crianças e adolescentes. Os resultados apontaram que a maior parte do tempo das crianças e adolescentes estava voltada para atividades de sono, descanso ou despertar. $O$ estudo averiguou que grande parte das atividades estavam relacionadas aos cuidados básicos, como alimentação e higiene.

No momento da atividade supervisionada de estágio, algumas crianças acolhidas frequentavam o Apoio Socioeducativo em Meio Aberto (ASEMA), que é um programa que visa dar assistência às crianças em situação de vulnerabilidade social indo ao encontro às orientações do Art. 90 do ECA (Presidência da República, 1990). O ASEMA era oferecido na sede da instituição de acolhimento para crianças entre seis e 12 anos da comunidade local, no turno inverso à escola, oferecendo reforço escolar, atividades educativas, oficinas de artesanato e instrumentos musicais, além da realização de esportes e atividades lúdicas. No entanto, para os adolescentes acolhidos, não era oferecida nenhuma atividade no local. A reduzida oferta de atividades pode trazer impacto no desenvolvimento das crianças e adolescentes. Nesse sentido, é importante ampliar as ações desenvolvidas no âmbito institucional, como inserir as crianças/adolescentes em atividades lúdicas, aulas de música, dança, línguas, atividades esportivas, entre outros. Possibilitar aos sujeitos acolhidos atividades externas à instituição promove outras vivências e permite que outras relações sejam estabelecidas, o que beneficia o desenvolvimento (Heumann \& Cavalcante, 2018). 
Diante deste desafio, as estagiárias e as psicólogas da instituição planejaram oficinas criativas para os adolescentes, inspiradas em experiências da área (Savegnago, Faraj, Arpini, \& Siqueira, 2015). Os encontros ocorreram de maneira quinzenal e em cada atividade era produzido um trabalho artístico (pulseira, mandala, entre outras). As oficinas foram desenvolvidas no segundo semestre de 2019 e se constituíram em um espaço de escuta, diálogo, elaboração de algumas vivências e reflexão de projetos de vida. Além das oficinas voltadas aos adolescentes, o estágio proporcionou às crianças da instituição e da comunidade, que participavam do ASEMA o Projeto intitulado "Afetarte: transformando vivências através do lúdico e da arte". Este visou, através da contação de histórias, desenvolver formas de expressão e convivência, divergentes das quais as crianças estavam acostumadas, de forma que atingisse os diversos níveis de desenvolvimento. Também teve como objetivos trabalhar as interações e a construção em grupo; e, tratar temáticas como violência, bullying e demais questões que se façam latentes. As atividades lúdicas são importantes para o desenvolvimento das crianças, estabelecimento dos vínculos afetivos e de confiança entre os pares, internalização das regras sociais/institucionais e elaboração das vivências (Villachan-Lyra, Queiroz, Moura, \& Gil, 2018). Este projeto tinha frequência quinzenal e atendeu cerca de 15 crianças.

Por fim, como proposta para futuras ações, ainda é possível considerar parcerias com universidades e/ou empresas privadas. Ou ainda, poderia ser realizado um mapeamento no Município de projetos sociais voltados para a população infantojuvenil, a fim de inserir as crianças e os adolescentes na comunidade, conforme preconizado na Legislação (Presidência da República, 1990). A oferta de atividades lúdicas e esportivas favorece o desenvolvimento humano, assim como promove a sua saúde mental. Oferecer atividades é uma forma de investimento e de pensar projetos de vida para esses jovens.

\section{DA POLÍTICA DE ATENDIMENTO}

Muitas crianças e os adolescentes acolhidos vivenciaram situações de violência e, dessa forma, atendimentos especializados, muitas vezes, são necessários, pois essas vivências trazem implicações no desenvolvimento social, físico e psíquico dos sujeitos (Habigzang, Azevedo, Koller, \& Machado, 2006). Crianças e adolescentes podem apresentar diferentes sintomas, entre eles, dificuldade de estabelecer relações com os pares, perda da autoestima, sentimento de culpa, medo excessivo, ansiedade, apatia, desinteresse pelas brincadeiras, regressão a comportamentos infantis, queixas somáticas, entre outros (Conselho Federal de Psicologia, 2009). Além disso, a experiência da separação, como acontece no acolhimento institucional, pode ser vivenciada como um luto na infância. "Tristeza, melancolia, medo - sentimentos intensos que podem ser manifestados por comportamentos de apatia, desânimo e agressividade" (Oliveira, 2007, p. 115). O atendimento especializado foi preconizado pelo ECA e vem sendo desenvolvido nos Centros de Referência Especializados da Assistência Social (CREAS), que é um articulador da proteção social de média complexidade, devendo ofertar orientações e apoio 
especializado e continuado aos sujeitos com seus direitos violados (Ministério do Desenvolvimento Social e Combate à Fome, 2009). Se constatada a necessidade de psicoterapia, o CREAS deve encaminhar para um serviço de Psicologia especializado de atenção às vítimas de violência. Além da necessidade do atendimento no CREAS, muitas vezes, crianças e adolescentes apresentam demandas de saúde mental, sendo necessário o atendimento especializado nos Centro de Atenção Psicossocial (CAPS), que compõem a rede de atenção à saúde mental, sendo integrante do Sistema Único de Saúde (SUS).

A partir do estágio, verificou-se que o atendimento especializado às vítimas de violência não era ofertado a muitas crianças/adolescentes, em especial, devido à grande demanda dos serviços existentes no Município. As crianças e adolescentes que precisavam de atenção terapêutica em decorrência da violência eram encaminhadas para um serviço de saúde mental de caráter generalista, e enfrentavam uma lista de espera. Não havia um serviço de Psicologia especializado de atenção às vítimas de violência nessa cidade. Sem a oferta imediata deste serviço, as estagiárias de Psicologia proporcionaram o atendimento especializado na clínica-escola da Universidade, na qual estavam vinculadas. No período de um ano de estágio, nove acolhidos foram atendidos, com demandas diversificadas. Os encaminhamentos das crianças e adolescentes para o atendimento clínico eram feitos pela equipe técnica. $\mathrm{Na}$ avaliação dos atendimentos, considerou-se que a psicoterapia poderia auxiliar a ressignificar experiências que levaram a situação de acolhimento, bem como fornecer espaços de escuta, expressão e de respeito à singularidade e história de vida de cada criança ou adolescente, contribuindo positivamente para seu desenvolvimento saudável. É importante considerar que essa alternativa não supriu a demanda por atendimento que muitas vezes a instituição possuía, sendo necessário investir na articulação com a rede de atendimento voltado para a saúde mental dessa população, constituindo-se como uma proposta futura prioritária do presente estágio. Marin (1998) mostrou que "o problema dessas crianças não era a perda da família, a falta e a separação, mas sim a impossibilidade de significar essa situação" (p. 78). A não oferta do atendimento especializado pode criar uma situação de desamparo, que, ainda segundo Oliveira (2007), parte de um impedimento do encontro das crianças com suas histórias de vida e da expressão de suas dores. Nesse sentido, apesar do ECA ter preconizado o atendimento psicossocial à criança e ao adolescente em situação de violência no ano de 1990, a oferta do atendimento na prática ainda é um desafio, exigindo o reconhecimento dessa falha e o investimento do setor público (Faraj et al., 2016).

\section{DO DIREITO À CONVIVÊNCIA FAMILIAR E COMUNITÁRIA}

De acordo com as Orientações Técnicas para Serviços de Acolhimento (2009), os serviços de acolhimento para crianças e adolescentes devem ser localizados em áreas residenciais, próximas da residência dos acolhidos, em termo socioeconômico e geográfico. Essa medida torna mais promissor o contato com a família e também com a comunidade, preservando os vínculos familiares e comunitários. No entanto, essa orientação nem sempre é cumprida, seja por que 
os familiares não visitam a criança, ou porque a instituição está localizada longe da comunidade dos acolhidos e/ou por a visita não ser incentivada pela equipe da instituição (Cruz et al., 2018). A garantia da convivência familiar e comunitária também estava entre as dificuldades vivenciadas no estágio acadêmico.

A neutralidade para a garantia do direito à convivência estava amparada nos sérios problemas das famílias como: dependência de substâncias ilícitas, fragilidade na saúde mental dos responsáveis da família e existência de práticas de violação de direitos. Por outro lado, o contexto institucional parecia acreditar que tais fatores se resolveriam sozinhos ou por meio dos recursos internos e externos das famílias, não a partir da oferta de atendimentos psicossociais regulares que pudessem fortalecer as famílias e seus recursos. A literatura tem evidenciado que as famílias desses jovens se encontram em situação de vulnerabilidade, vivenciando diversificadas carências, como moradia, saúde, alimentação, educação, emprego, entre outras. Também se encontram expostas a situações de risco e muitas vezes não dispõe de recurso para modificar a situação que se encontra. Na maioria das vezes, trata-se de famílias com questões sociais complexas e que exige diversas intervenções (Fonseca \& Koller, 2018). Nesse sentido, garantir o direito da criança à convivência familiar é dispor de um horário para escutar as necessidades dos membros familiares e elaborar um plano de atendimento pautado nas suas necessidades e demandas. Na maioria dos casos, é necessário o atendimento psicológico e social periódico à família, o encaminhamento para serviços de atendimento, a busca pelo emprego e/ou direitos sociais. O acompanhamento e as intervenções indicarão se o retorno da criança/adolescente à família será possível ou se haverá a indicação de destituição familiar e encaminhamento para famílias substitutas (Fonseca \& Koller, 2018).

Considerando esse desafio, foi proposto pelo estágio o fortalecimento dos atendimentos psicossociais às famílias das crianças e adolescentes acolhidos. Este consistiu na escuta dos membros familiares, análise das necessidades, planejamento para a reinserção e acompanhamento desse processo. Uma outra estratégia para fortalecer os laços familiares poderia ser os programas de aperfeiçoamento de práticas educativas parentais que são considerados por estudos um instrumento fundamental para ajudar a pais e cuidadores a fornecer um cuidado mais eficaz, propiciando um desenvolvimento saudável aos filhos (Guisso, Bolze, \& Viera, 2019). No caso de pais de adolescentes, esses programas podem ser ainda mais efetivos por conta da multiplicidade de situações que o adolescente está lidando nessa etapa do desenvolvimento (Bock, 2007).

Na prática do estágio, também foi identificado o desmembramento de irmãos nas casas lares. A separação ocorria a fim de romper vínculos e facilitar o processo de adoção, sendo justificada, muitas vezes, devido conflitos entre os irmãos ou outro acolhido. No entanto, esta medida não está prevista na legislação vigente, pelo contrário, recomenda-se o não desmembramento de grupos de irmãos, pois preconiza a prevenção dos vínculos familiares (Presidência da República, 1990). Segundo Bowlby (1969/2002), a quebra dos laços afetivos pode ser decisiva para 
o desenvolvimento da criança, pois tanto a estimulação como o fornecimento de uma base segura a ser exercida pelas pessoas mais próximas, nesse caso os irmãos, possibilitam à criança o estabelecimento de vínculos afetivos saudáveis. Ademais, pode-se salientar que o convívio entre irmãos pode ser considerado uma importante fonte de apoio e facilitador ao enfrentamento da situação de acolhimento. Carreirão (2005) afirma que os irmãos podem representar referência de apego, principalmente por possuírem as mesmas vivências familiares, justificando, assim a importância da manutenção do vínculo e da proximidade entre irmãos. Esse aspecto poderá ser trabalhado nas próximas etapas do estágio e em conjunto com toda a instituição, visto que se precisa aperfeiçoar as formas de resolução de conflitos e transmitir aos acolhidos o ensinamento que se pode resolver problemas sem romper. Dessa forma, acredita-se que para minimizar os conflitos entre os acolhidos e evitar a quebra dos vínculos, poderia ser implementado na instituição o Treinamento de Habilidades Sociais (THS), no qual vem sendo desenvolvido em diferentes contextos e apresentando resultados positivos, entre eles: melhora no convívio entre os pares, aprendizado de técnicas de relaxamento, aprimoramento de habilidades sociais (Pasche, Vidal, Schott Barbosa, \& Vasconcellos, 2019), aumento nas habilidades de cooperação, responsabilidade e autocontrole (Batista \& Maturino, 2015).

Ainda quanto à garantia da convivência comunitária, foram observadas a necessidade de maiores esforços pela procura de atividades fora da instituição e a carência destas ofertas. Salienta-se que a convivência comunitária poderia ser garantida através da participação das crianças e dos adolescentes nos eventos e atividades promovidos no bairro e escola. A literatura menciona que também é importante que as crianças e adolescentes possam receber os amigos na instituição, participar de festa de aniversário dos amigos e colegas, entre outras possibilidades (Cruz et al., 2018).

\section{TEMPO DE PERMANÊNCIA NA INSTITUIÇÃO}

Ainda que a legislação defina que o tempo de acolhimento deverá ser no máximo dois anos, salvo comprovada necessidade que atenda ao interesse da criança/adolescente (Presidência da República, 2009), havia muitos acolhidos que estavam há mais de dois anos na Instituição. O prolongado tempo de acolhimento parece ser um fator de risco importante de ser considerado, visto que estudos têm indicado que, somado ao prejuízo nos laços familiares, um período longo de acolhimento pode levar a um atraso no desenvolvimento cognitivo e afetivo, bem como a um comportamento agressivo, sintomas de depressão e ansiedade (Álvares \& Lobato, 2013; Assis \& Farias, 2013). O prolongamento do tempo de acolhimento pode levar a baixo desempenho escolar, baixa autoestima, baixo senso de competência em si e de confiança nos outros, repetência escolar e uso precoce de substâncias psicoativas (Abaid, Dell'Aglio, \& Koller, 2010; Siqueira \& Dell'Aglio, 2010). 
Entre as justificativas identificada no estágio supervisionado estava a demora nos processos judiciais, referentes aos pedidos de destituição de poder familiar, que ficavam meses sem resposta do Juizado da Infância e Juventude. Outra justificativa para que jovens estivessem no acolhimento mais de dois anos foi a reduzida possibilidade de efetivar adoções de crianças maiores e adolescentes. Nesse sentido, o Programa de Apadrinhamento Afetivo poderia ser uma alternativa para ampliar a rede de apoio pessoal dos acolhidos e minimizar os efeitos do acolhimento prolongado. O apadrinhamento afetivo é previsto pelo Plano Nacional de Promoção, Proteção e Defesa do Direito de Crianças e Adolescentes à Convivência Familiar e Comunitária (2006) como programa que permite que pessoas da comunidade contribuam, financeira e afetivamente, para o desenvolvimento de pessoas em acolhimento institucional. Esse programa conta com "padrinhos/madrinhas voluntários previamente selecionados e preparados, ampliando, assim, a rede de apoio afetivo, social e comunitário para além do abrigo" (p. 126). As Orientações Técnicas para Serviços de Acolhimento (2009) trazem que Programas de Apadrinhamento Afetivo devem priorizar as crianças e os adolescentes com previsão de permanência maior no serviço, ou seja, aqueles sem perspectiva de retorno familiar ou adoção. Ainda que se reconheça a necessidade de aperfeiçoamento do programa, no sentido de não se constituir em um novo rompimento de vínculo, ele poderia constituir-se em uma oportunidade para construir vínculos fortes e duradouros com pessoas da comunidade, a fim de criarem laços de confiança e uma relação de pertencimento com essas pessoas.

Outra possibilidade seria a inserção dos acolhidos em famílias acolhedoras. Plano Nacional de Promoção, Proteção e Defesa do Direito de Crianças e Adolescentes à Convivência Familiar e Comunitária (2006) prevê a modalidade de acolhimento familiar, através do "Serviço de Acolhimento em Família Acolhedora", regulamentado em suas particularidades pelas Orientações Técnicas para Serviços de Acolhimento (2009). Essa modalidade de acolhimento está em plena expansão no Brasil e tem sido considerada promissora, embora não tenha sido implantada na cidade em que o trabalho foi realizado. "Para as crianças pequenas que vivenciam situações de violação de direitos, o acolhimento familiar tem se mostrado uma forma de atendimento adequada a suas especificidades" (p. 83). Assim, para a efetividade dos direitos da criança e do adolescente, faz-se necessário pensar nessas alternativas, pois o acolhimento deixa de ser protetivo no momento em que a rede de proteção não consegue proporcionar para essas crianças e adolescentes a colocação em família, seja a ampliada ou uma substituta, contrariando os princípios do ECA (Presidência da República, 1990).

Quanto aos adolescentes, cabe problematizar as possibilidades de residirem em repúblicas, modalidade de acolhimento que possibilitaria que o adolescente exercesse sua autonomia sob supervisão e acompanhamento. Contudo, essa modalidade não estava disponível no Município em que o estágio supervisionado foi realizado. Nesse ponto, a legislação vigente deixa as crianças de idade avançada e os adolescentes em uma espécie de "limbo" quando não há possibilidades de reintegração familiar nem de adoção. Essas crianças e adolescentes acabam 
crescendo dentro da instituição, muitas vezes sem uma referência fixa de família (devido à rotatividade de educadores e de outros acolhidos) e, consequentemente, com os recursos psíquicos frágeis para enfrentar a vida adulta ao completar 18 anos (Moré \& Sperancetta, 2010).

\section{CONSIDERAÇÕES FINAIS}

O Estatuto da Criança e do Adolescente constitui em uma importante ferramenta de garantia de cidadania para indivíduos em situação de desenvolvimento, estando o Brasil em destaque por conta da sua implementação. Contudo, a experiência do estágio supervisionado em uma instituição de acolhimento para crianças e adolescentes possibilitou constatar alguns desencontros entre as legislações vigentes (Presidência da República, 1990, 2009) e a prática, sendo um trabalho árduo o da efetivação da lei.

Do ponto de vista da formação em Psicologia, a experiência foi considerada potente pelas estagiárias, possibilitou a interlocução entre a teoria e o campo da prática, além de favorecer a construção do senso de compromisso social e concretizar os ensinamentos teórico-prático-éticos. Pode-se constatar a complexidade do ambiente institucional na prática, integrando os conteúdos teóricos aos desafios da prática. No que tange ao ECA, pode-se observar a complexidade e os inúmeros impasses que obstaculizam a sua efetivação, sendo um trabalho permanente, feito em conjunto e de poucos passos. Com essa experiência, as estudantes qualificaram suas formações e puderam avançar nos seus processos internos de identidade com a profissão que escolheram.

Os desafios encontrados na prática estavam relacionados a garantia do direito à educação, cultura, lazer, esporte, atendimento especializado, convivência familiar e comunitária. Também estavam relacionados ao tempo de permanência na instituição de acolhimento. Através da experiência de um ano no local de estágio e das questões problematizadas, algumas intervenções foram promovidas: reinserção dos adolescentes à escola, a partir do Programa do Jovem Aprendiz; atendimento clínico especializado; atendimentos psicossociais com familiares dos acolhidos; desenvolvimento do projeto Afetarte com crianças do projeto ASEMA e de oficinas criativas para adolescentes acolhidos. No entanto, ainda se faz necessário promover outras ações e fortalecer as que já foram desenvolvidas. Os acolhidos necessitam de atividades lúdicas, culturais e esportivas que invistam em suas potencialidades e em seu desenvolvimento biopsicossocial, sejam estas atividades tanto internas, quanto externas à instituição. Também o olhar à família precisa ser priorizado e continuado.

A partir da prática, identifica-se que alguns desafios podem ser superados através das ações desenvolvidas tanto pela instituição de acolhimento quanto pelo sistema de justiça, saúde e educação. Entende-se que o processo de aperfeiçoamento da execução da lei é constante e dinâmico e a busca por esse alinhamento é o primeiro passo para que as crianças e os adolescentes possam estar em proteção e 
desenvolvendo suas potencialidades. Nesse sentido, ações em rede podem possibilitar a efetivação dos direitos das criança e adolescente preconizados no ECA. A legislação voltada para a criança e o adolescente buscou garantir os direitos, no entanto é necessário avançar na efetivação destes direitos por meio de um constante esforço de todos os níveis da sociedade.

\section{REFERÊNCIAS}

Abaid, J. L. W., Dell'Aglio, D. D., \& Koller, S. H. (2010). Preditores de sintomas depressivos em crianças e adolescentes institucionalizados. Universitas Psychologica, 9(1), 199-212. https://doi.org/10.11144/Javeriana.upsy9-1.psdc

Acioli, R. M. L., Barreira, A. K., Lima, M. L. C., Assis, S. G., \& Lima, M. L. L. T. (2019). Tempo de acolhimento e características dos adolescentes acolhidos por tipo de serviços institucionais. Recife, Brasil 2009-2013. Ciência \& Saúde Coletiva, 24(2), 553-562. https://doi.org/10.1590/141381232018242.06402017

Álvares, A. de M., \& Lobato, G. R. (2013). Um estudo exploratório da incidência de sintomas depressivos em crianças e adolescentes em acolhimento institucional. Temas em Psicologia, 21(1), 151-164. http://dx.doi.org/10.9788/TP2013.1-11

Assis, S. G., \& Farias, L. O. P. (Eds.). (2013). Levantamento nacional das crianças e adolescentes em serviço de acolhimento. São Paulo, SP: Hucitec.

Batista, S. V., \& Marturano, E. M. (2015). Intervenção para promover habilidades sociais e reduzir problemas de comportamento de crianças em um núcleo social. Pesquisa Prática Psicossociais, 10(2), 313-326. Recuperado em 29 de junho de 2021, de http://pepsic.bvsalud.org/scielo.php?script=sci_arttext\&pid=S1809$89082015000200009 \&$ lng =pt\&tlng=pt.

Bock, A. M. B. (2007). A adolescência como construção social: Estudo sobre livros destinados a pais e educadores. Revista Semestral da Associação Brasileira de Psicologia Escolar e Educacional (ABRAPEE), 11(1), 63-76. https://doi.org/10.1590/S1413-85572007000100007

Bowlby, J. (2002). Apego e perda: Apego (A. Cabral, Trad.). São Paulo, SP: Martins Fontes (Original publicado em 1969).

Cano, M. A. T., Ferriani, M. G. C., \& Mendonça, M. L. (1999). Repetência e evasão escolar de adolescentes em Ribeirão Preto-SP: uma primeira abordagem. Revista Eletrônica de Enfermagem (online), 1(1), 1-10. Recuperado em 29 de junho de 2021 de https://revistas.ufg.br/fen/article/view/663/739.

Conselho Federal de Psicologia. (2009). Serviço de proteção social a crianças e adolescentes vítimas de violência, abuso e exploração sexual e suas famílias: Referências para a atuação do psicólogo. Brasília, DF: CFP.

Cruz, D. A., Cardoso, A. M., \& Matos, E. P. (2018). Conviver é preciso: Reflexão acerca do direito à convivência comunitária de crianças e adolescente em acolhimento institucional. In L. I. C. Cavalcante, C. M. C. Magalhães, L. S. Corrêa, E. F. Costa, \& D. A. Cruz (Eds.), Acolhimento institucional de criança e adolescente: Teoria e evidencia para boas práticas (pp. 101-112) Curitiba, PR: Juruá.

Da Silva, A. B., \& Costa, A. V. (2019). Políticas e programas públicos que oportunizam a inserção do jovem no mercado de trabalho. Id On Line Revista Multidisciplinar e de Psicologia, 13(43), 967-981. Recuperado em 29 de junho de 2021 de https://idonline.emnuvens.com.br/id/article/download/1571/2317.

Faraj, S. P., Siqueira, A. C., \& Arpini, D. M. (2016). O atendimento psicológico no centro de referência especializado da assistência social e a visão de operadores do direito e conselheiros tutelares. Estudos de Psicologia (Campinas), 33(4), 757-766. https://doi.org/10.1590/198202752016000400018

Fonseca, H. R. R., \& Koller, S. H. (2018). Acompanhamento familiar e cartilha da família com crianças e adolescente em acolhimento. In L. I. C. Cavalcante, C. M. C. Magalhães, L. S. Corrêa, E. F. Costa, \& D. A. Cruz (Eds.), Acolhimento institucional de criança e adolescente: Teoria e evidencia para boas práticas (pp. 101-112). Curitiba, PR: Juruá. 
Guisso, L., Bolze, S. D. A., \& Viera, M. L. (2019). Práticas parentais positivas e programas de treinamento parental: Uma revisão sistemática da literatura. Contextos Clínicos, 12(1), 226-255. https://doi.org/10.4013/ctc.2019.121.10

Habigzang, L. F., Azevedo, G. A., Koller, S. H., \& Machado, P. X. (2006). Fatores de risco e de proteção na rede de atendimento a crianças e adolescentes vítimas de violência sexual. Psicologia: Reflexão e Crítica, 19(3), 379-386. https://doi.org/10.1590/S0102-79722006000300006

Heumann, I. S., \& Cavalcante, L. I. C. (2018). Rotinas de crianças e adolescentes em acolhimento institucional: Estudo descritivo. Arquivos Brasileiros de Psicologia, 70(2), 22-37.

Presidência da República (1990). Lei no 8.069, de 13 de julho de 1990. Dispõe sobre o Estatuto da Criança e do Adolescente e dá outras providências. Diário Oficial da União. Brasília, DF. Recuperado de http://www.planalto.gov.br/ccivil_03/leis/l8069.htm

Presidência da República (2009). Lei $n^{\circ} 12.010$, de 3 de agosto de 2009. Dispõe sobre adoção; altera as Leis nos 8.069, de 13 de julho de 1990 - Estatuto da Criança e do Adolescente, 8.560, de 29 de dezembro de 1992; revoga dispositivos da Lei $n^{\circ}$ 10.406, de 10 de janeiro de 2002 - Código Civil, e da Consolidação das Leis do Trabalho - CLT, aprovada pelo Decreto-Lei $n^{\circ} 5.452$, de $1^{\circ}$ de maio de 1943; e dá outras providências. Diário Oficial da União. Brasília, DF. Recuperado de http://www.planalto.gov.br/ccivil_03/_ato2007- 2010/2009/ lei/l12010.htm.

Machado, M. S., Scott, J. B., \& Siqueira, A. C. (2016). Crianças institucionalizadas e suas famílias de origem: As imagens sociais e seus reflexos na garantia de direitos. Revista Brasileira de Iniciação Científica, 3(6), 91-111. Recuperado em 29 de junho de 2021 de https://periodicos.itp.ifsp.edu.br/index.php/IC/article/view/460/459.

Marin, I. S. K. (1998). Sujeito, Desamparo e Violência. Revista Latinoamericana de Psicopatologia Fundamental, 2(3), 75-88. https://doi.org/10.1590/1415-47141999003005

Martinez, A. L. M., \& Soares-Silva, A. P. (2008). O momento da saída do abrigo por causa da maioridade: A voz dos adolescentes. Psicologia em Revista, 14(2), 113-132. Recuperado em 29 de junho de 2021 de http://pepsic.bvsalud.org/pdf/per/v14n2/v14n2a08.pdf.

Ministério do Desenvolvimento Social e Combate à Fome. (2009). Orientações técnicas para serviços de acolhimento para crianças e adolescentes. Brasília, DF: Ministério do Desenvolvimento Social e Combate à Fome.

Ministério do Trabalho e Emprego (2014). Manual de Aprendizagem: O que é preciso saber para contratar o aprendiz (Ed. revista e ampliada). Recuperado de acesso.mte.gov.br/políticas_juventude/manualdeaprendizagem

Moré, C. L. O. O., \& Sperancetta, A. (2010). Práticas de pais sociais em instituições de acolhimento de crianças e adolescentes. Psicologia \& Sociedade, 22(3), 519-528. https://doi.org/10.1590/S0102-71822010000300012

Oliveira, R. C. S. (2007). Quero voltar para casa: O trabalho em rede e a garantia do direito à convivência familiar e comunitária para crianças e adolescentes que vivem em abrigo. São Paulo, SP: Associação de Assistentes Sociais e Psicólogos do Tribunal de Justiça de São Paulo AASPTJ/SP

Pasche, A. D., Vidal, J. L., Schott, F., Barbosa, T. P., \& Vasconcellos, S. J. L. (2019). Treinamento de habilidades sociais no contexto escolar: Um relato de experiência. Revista de Psicologia da IMED, 11(2), 166-179. https://doi.org/10.18256/2175-5027.2019.v11i2.2850

Presidência da República. Secretaria Especial dos Direitos Humanos. Ministério do Desenvolvimento Social e Combate à Fome. (2006). Plano Nacional de Promoção, Proteção e Defesa do Direito de Crianças e Adolescentes à Convivência Familiar e Comunitária. Brasília, DF: CNAS, CONANDA, SEDH, MDS.

Savegnago, S. D. O., Faraj, S. P., Arpini, D. M, \& Siqueira, A. C. (2015). Oficinas com meninas em uma escola aberta: Espaço de diálogo, reflexão e reconhecimento da singularidade. Temas em Psicologia, 23(2), 467-480. http://dx.doi.org/10.9788/TP2015.2-17

Siqueira, A. C., \& Dell'Aglio, D. D. (2010). Crianças e adolescentes institucionalizados: Desempenho escolar, satisfação de vida e rede de apoio social. Psicologia: Teoria e Pesquisa, 26(3), $407-$ 415. https://doi.org/10.1590/S0102-37722010000300003

Villachan-Lyra, P., Queiroz, E. F. F., Moura, R. B., \& Gil, M. O. G. (2018). Entendendo o desenvolvimento infantil: Contribuições das neurociências e o papel das relações afetivas para pais $e$ educadores. Curitiba, PR: Appris. 


\section{CONFLITOS DE INTERESSES}

Não há conflito de interesses.

\section{SOBRE OS AUTORES}

Aline Cardoso Siqueira é Docente dos Programas de Pós-Graduação em Ciências da Saúde e Psicologia da Universidade Federal de Santa Maria-RS. Pesquisadora de Produtividade do CNPq Nível 2.

E-mail: alinecsiq@gmail.com

(2) https://orcid.org/0000-0003-1430-9722

Suane Pastoriza Faraj é Psicóloga, Doutoranda do Programa de Pós-Graduação em Psicologia da Universidade Federal de Santa Maria-RS.

E-mail: suanef@yahoo.com.br

(2) https://orcid.org/0000-0002-8013-0213

Daiane Santos do Carmo Kemerich é Graduanda em Psicologia na Universidade Federal de Santa Maria-RS.

E-mail: daianesckemerich@gmail.com

000-0002-9012-7392

Amanda Pereira da Silva é Graduanda em Psicologia na Universidade Federal de Santa Maria-RS. E-mail: amandapereiradasilva40@gmail.com

(3) https://orcid.org/0000-00017712-7796

Daniela Porto Giacomelli é Graduanda em Psicologia na Universidade Federal de Santa Maria-RS. E-mail: danocaa@gmail.com

(3) https://orcid.org/0000-0002-8095-2268 